\title{
AZYGOS VEIN INJURY IN BLUNT CHEST TRAUMA
}

\author{
Pavel Drac ${ }^{a *}$, Pavel Manak ${ }^{\mathrm{a}}$, Jiri Klein ${ }^{\mathrm{b}}$, Vladimir Kral ${ }^{\mathrm{b}}$ \\ ${ }^{a}$ Department of Traumatology, Teaching Hospital, Olomouc \\ ${ }^{b} I^{s t}$ Clinic of Surgery, Teaching Hospital, Olomouc \\ *e-mail: dracpa@fnol.cz
}

Received: August 28, 2007; Accepted: September 16, 2007

Key words: Azygos vein rupture/Blunt chest trauma/Massive haemothorax/Right thoracotomy

Injuries to the azygos vein in a blunt chest trauma are uncommon and have previously been described in only 21 cases. The diagnosis is crucially based on massive right haemothorax with signs of shock, hypotension and altered mental status. The severity of the trauma, speed of transport and surgical intervention are often decisive for the survival of the patient. This is confirmed by the three cases we report below.

\section{INTRODUCTION}

In developed European countries, chest trauma plays a major role in one out of two deaths resulting from road traffic accidents, with fifty percent of the injured dying within two hours. Non-penetrating traumata are predominant. The most common cause of death is the rupture of the aorta, the brachiocephalic trunk and the subclavian artery. Ruptures of the azygos vein are rare and little known. Since 1978, literature worldwide has presented as few as 21 clinical case reports, with four ruptures identified in postmortem examination ${ }^{1-18}$.

We present three cases treated from 1997 to 2002 at the Department of Traumatology, Teaching Hospital in Olomouc.

\section{CASE REPORT 1}

A 36-year-old pedestrian was admitted to hospital following a head-on car collision. His vital signs were: blood pressure $70 / 50 \mathrm{mmHg}$ and heart rate of 130 . He was intubated on the scene. Examination initially disclosed diminished breath on the right, and tube thoracostomy drained $2000 \mathrm{ml}$ of dark blood. The patient was immediately taken to the operating theatre and a right anterolateral thoracotomy was performed with the finding of approximately $500 \mathrm{ml}$ of blood. The azygos vein was confirmed to be the only source of bleeding due to disruption of its arch $1 \mathrm{~cm}$ ahead of its entry in the superior vena cava. The arch was ligated with the suture proximally and distally. Exploration of the right thoracic cavity revealed fracture of the posterior part of the $2^{\text {nd }}$ rib. Postoperatively, the CT examination found multiple brain contusion centres and decompresion craniotomy was performed 48 hours after the ligation of the azygos vein because of a growing brain oedema. The patient was discharged from hospital on the 22nd day after the trauma. During the re-examination five years later he was in completely good health.

\section{CASE REPORT 2}

A 22-year-old driver involved in a motoring accident (car vs. car collision) was admitted to hospital. He was intubated before admission. Initially, the patient's blood presure was $130 / 80 \mathrm{mmHg}$ and the heart rate was $110 \mathrm{bpm}$. Clinical, X-ray and CT examinations identified multiple fractures of the facial skeleton, brain contusion, ruptured spleen, and right hemothorax (ISS = 42). After immediate right tube thoracostomy with blood loss of $700 \mathrm{ml}$, urgent laparotomy with splenectomy was performed. Subsequent right thoracotomy revealed azygos vein breach, which was treated by ligation. Due to increasing bleeding from the facial region, maxillofacial surgery was performed. Despite intensive resuscitation, disseminated intravascular coagulopathy developed and the patient died.

\section{CASE REPORT 3}

The last patient was a 58-year-old driver, also involved in a motoring accident. Due to the length of long time required to extract the patient from his destroyed vehicle, he was admitted to hospital 85 minutes after the injury. $\mathrm{He}$ had been intubated, with systolic the blood pressure of $90 \mathrm{mmHg}$ and tachycardia. During intravenous resuscitation the X-ray of the head, cervical spine, thorax and pelvis disclosed fractures of the $5^{\text {th }}$ to $7^{\text {th }}$ right ribs, right haemo-pneumothorax, fractures of the right maxilla, sacrum and acetabulum. After the application of chest drainage and evacuation of air, accentuated bleeding of 700 $\mathrm{ml} / \mathrm{h}$ was demonstrated, requiring surgical intervention in the thoracic cavity with findings of lung dilaceration and rupture of the azygos vein. The rupture was treated by ligation and the right thorax was drained. Post-surgery CT examination revealed a malignant brain oedema. The patient's overall condition corresponded to a severe cerebral trauma and he died 1 day after the surgery. 


\section{DISCUSSION}

The azygos vein is positioned in the posterior mediastinum, where it penetrates from the retroperitonium through the diaphragm. It is located on the right side of the thoracal vertebrae. On the level of the $4^{\text {th }}$ thoracal vertebra it circles the right bronchus from behind and above to enter the superior vena cava proximal to its investment by the pericardium. It receives the posterior intercostal veins from the $4^{\text {th }}$ and $12^{\text {th }}$ intercostal spaces as well as the subcostal vein and the hemiazygous vein, which enters between the $7^{\text {th }}$ and $9^{\text {th }}$ thoracal vertebrae.

The following three injury mechanisms are presumed according to the reported cases ${ }^{2,5-7}$. Violent axial or rotary force applied to the relatively mobile arch of the azygos vein caused by sudden deceleration, sudden increase in venous pressure resulting from the heart compression between the sternum and the vertebral column or from the compression of the peritoneal cavity, or both and fracture of a vertebra close to the vein.

Thoracic vein injuries are usually demonstrated by signs of shock, including tachycardia, hypotension and altered mental status. Physical examination may reveal signs of hemothorax. Chest radiography may show opacification of the right hemithorax or a wide mediastinum ${ }^{3,7,8}$. Snyder ${ }^{5}$ described a patient with the initial chest radiography clear except for some haziness of the borders of the diaphragm and fractures of the two ribs on the left. Sugimoto ${ }^{9}$ recapitulated achievable reports and found positive initial chest radiography in $90 \%$ cases. The patient's overall condition mostly excludes the performance of CT examination.

Right chest tube placement confirms right haemothorax and massive bleeding with persistent hypotension makes further diagnostic tests unnecessary. Bowles et al. ${ }^{2}$ quotes the guidelines of the Committee on Trauma of the American College of Surgeons. According to their recommendation, $1500 \mathrm{ml}$ initially or more than $200 \mathrm{ml}$ per hour for 2 to 4 hours are the criteria for emergent thoracotomy. Since treatment of an azygos vein injury requires rapid evaluation and resuscitation and any delay decreases the survival rate of these patients, we adhere to a patient's overall condition rather then the amount of the blood loss.

An overwhelming majority of authors give priority to right thoracotomy as the approach for surgery of the vena azygos rupture ${ }^{1-3,5-17}$. Only Cagini et al..$^{18}$ used median sternotomy in the presented patient. We prefer right thoracotomy for its immediacy and simplicity. There were no attempts at reconstruction of reported azygos vein ruptures. In all operated patients the ruptured azygos vein was ligated ${ }^{1-3,5,6,8,10-18}$, which was the method that we also employed.

The majority of the reported patients are successfully surgically treated ones. Only Sugimoto ${ }^{9}$, Walsh ${ }^{7}$ and Jain (ref. ${ }^{1}$ ) referred to patients who died in the operating room and Shkrum ${ }^{4}$ published four ruptures identified in postmortem examination. Nevertheless, we assume that the real frequency and mortality values of these injuries are much higher.

\section{CONCLUSION}

We presume that ruptures of the azygos vein are more frequent than the occurrence suggested by the published reports. This injury must be kept in mind in blunt chest trauma involving shock, particularly in the case of frontseat passengers involved in car collisions. This may be demonstrated by shock, dyspnoea, significant right-sided blood loss from chest drainage and (patient's condition permitting) X-ray or CT examinations. The patients may be conscious, but their life is in immediate danger. The speed of transport and surgical intervention is often decisive for the survival of the patient.

\section{REFERENCES}

1. Nguyen LL, Gates JD. Simultaneous azygos vein and aortic injury from blunt trauma: case report and review of the literature. J Trauma 2006; 61:444-446.

2. Bowles BJ, Teruya T, Belzberg H, Rivkind AI. Blunt traumatic azygous vein injury diagnosed by computed tomography: case report and review of the literature. J Trauma 2000; 49:776-779.

3. Sharma OP, Rawitscher RE. Blunt vena azygos trauma: report of a case and review of world literature. J Trauma 1999; 46:192-195.

4. Shkrum MJ, Green RN, Shum DT. Azygos vein laceration due to blunt trauma. J Forensic Sciences 1991; 36:410-421.

5. Snyder CL, Eyer SD. Blunt chest trauma with transection of the azygos vein: case report. J Trauma 1989; 29:889-890.

6. Spagliardi E, Palombo D. (1978) Considerazioni su un caso di rottura isolata della vena azygos. Minerva Cardioangiologica 1978; 26:637-639.

7. Walsh A, Snyder HS. Azygos vein laceration following a vertical deceleration injury. J Emerg Med 1992; 10:35-37.

8. Baldwin JC, Oyer PE, Guthaner DF, Stinson EB. Combined azygous vein and subclavian artery injury in blunt chest trauma. J Trauma 1984; 24:170-171.

9. Sugimoto K, Asari Y, Hirata M, Imai H, Ohwada T. The diagnostic problem associated with blunt traumatic azygous vein injury: delayed appearance of right haemothorax after blunt chest trauma. Injury 1998; 29:380-382.

10. Butler DA, Schneider RF, Jadali M. Traumatic injury to the azygos vein: case report. J Trauma 1995; 39:761-762.

11. Coates GR, Hall DP. Rupture of the azygos vein: an unusual cause of hemothorax due to blunt trauma. J Tenn Med Assoc 1987; $80: 155-156$.

12. Inoue $\mathbf{H}$, Iwasaki $\mathbf{M}$, Shirota $\mathrm{S}$, Ogawa $\mathbf{J}$, Shohtsu $\mathrm{A}$. Total avulsion of the azygos vein and longitudinal laceration of the mediastinal pleura due to blunt chest trauma: A case report. J Cardiovasc Surg 1993; 34:67-68.

13. Rebel A, Ellinger K, van Ackern K. Neue Airbag-assoziierte Verletzungsmuster nach Verkehrsunfällen. Anaesthesist 1996; 45:359-362.

14. Salizzoni M, Ardissone F, Borasio P, Dei Poli M. La rottura isolata della vena azygos da trauma toracico contusivo. Minerva Chirurgica 1980; 35:1255-1256.

15. Sherani TM, Fitzpatrick GJ, Phelan DM, O’Brien D, Al Tarief H, Neligan MC. Ruptured azygos vein due to blunt chest trauma. $\mathrm{Br}$ J Surg 1986; 73:885.

16. Thurman RT, Roettger R. Intrapleural rupture of the azygos vein. Ann Thorac Surg 1992; 53:697-699.

17. Walz M, Kolbow B, Auerbach F, Fernandez-Laser C, Eppen R. Ruptur der V. azygos beim stumpfen Thoraxtrauma. Unfallchir 2003; 106:764-767.

18. Cagini L, Boaron M, Corneli G, Gambale G. Rupture of the azygos vein in blunt chest trauma. J Cardiovasc Surg 1998; 39:249-250. 